\title{
Rhetorical Space and the Ontogeny of Women in the DDC
}

\author{
Melodie J. Fox \\ University of Wisconsin-Milwaukee \\ School of Information Studies \\ PO Box 413 \\ Milwaukee, WI 53201 \\ msjoblad@uwm.edu
}

\begin{abstract}
Keywords
Rhetoric, women, gender, Dewey Decimal Classification, $D D C$, ontogeny.

\section{EXTENDED ABSTRACT}

It is well-established that classification standards have historically reflected hierarchy, power and knowledge in the culture from which they originate (Olson, 2002). Budd (2003) describes classification as an agent of "symbolic power," and points out that without seeing classification as a "discursive act," class differences can be perpetuated ( $p$. 28). Placement of subjects in a classification scheme constitutes a rhetorical act that explicates an intentional or unintentional power strategy of the classification scheme's editors as perpetuators of the dominant culture. As cultural norms shift, so does the classification, creating an ontogeny, or what Tennis calls, "the life of the subject over time" $(2007,2012)$. If ontogeny tracks the arc of a subject's position, within each rendition of a classification the concepts proximate to each other to create a "rhetorical space" that defines how the concept should be perceived by users of the classification. Lorraine Code (2005) describes a rhetorical space as:
\end{abstract}

locations whose (tacit, rarely spoken) territorial imperatives structure and limit the kinds of utterances that can be voiced within them... with an expectation of being heard, understood, taken seriously. (p. ix)

Rhetorical spaces are not neutral, but rather

textured locations where it matters who is speaking and where and why, and where such mattering bears directly upon the possibility of

Advances in Classification Research, 2012, October 26, 2012, Baltimore, $\mathrm{MD}$, USA. knowledge claims, moral pronouncements, descriptions of "reality" achieving acknowledgement. (p. x)

Code asks where knowledge is being created, whose knowledge it is, and she identifies where authority is allowed, denied or silenced, and by whom. As moral agents, editors and editorial boards of classification schemes, in Code's terms, have a responsibility to see and have empathy for the people and concepts they name, and this respect must be demonstrated in the rhetorical space of the scheme. A rhetorical space is where all, regardless of culture or background, should be "heard, understood, [and] taken seriously" (p. ix).

The evolution from absence to ubiquity of women's topics in DDC shows growing respect for women in terms of Code's prerequisites for a rhetorical space; yet, the practical application results in a non-comprehensive view of women's topics that violates Cutter's principles for the library catalog. Do the methods of adaptation need to result in ameliorative change that provides equitable rhetorical space for marginalized groups? Or, on the other hand, should complex, monolithic entities be scrapped entirely when resources can be found with a bit of practice and the help of a reference librarian? A virtual rhetorical space could allow boundaries to shift and be permeated, allowing for multiple identifications without hierarchy, a space with a structure that grants "acknowledgement within complex and perplexing situations" (Code, 2005, p. xi). These are all questions with which the next generation of catalogers and researchers will grapple.

In this ongoing research, the ontogeny of the subject of women has been traced, as has the changing rhetorical space around "women" in various renderings of the DDC. Remaining questions to be addressed include the analysis of the results, and broader conclusions regarding what this means to classification as a whole.

\section{REFERENCES IN THE ABSTRACT}

Budd, J. (2003). The library, praxis, and symbolic power. Library Quarterly, 73(1), 19-32. 
Code, L. (1995). Rhetorical spaces: Essays on gendered locations. New York: Routledge.

Olson, H.A. (2002). The power to name: Locating the limits of subject representation in libraries. Boston: Kluwer Academic.

Tennis, J.T. (2007). Scheme versioning in the semantic web. Cataloging andClassification Quarterly, 43, $85-104$.

Tennis J.T. (2012). The strange case of eugenics: A subject's ontogeny in a long-lived classification scheme and the question of collocative integrity. Journal of the American Society for Information Science \& Technology 63(7), 1350-1359. DOI: 10.1002/asi.22686

\section{SELECTED REFERENCES FROM THE RESEARCH}

Ten Editions of the Dewey Decimal Classification

Biesecker, B. (1993). Coming to terms with recent attempts to write women into the history of rhetoric. Rethinking the history of rhetoric: Multidisciplinary essays on the rhetorical tradition. Ed. Takis Poulakis. Boulder: Westview Press.

Foss, K.A., Foss, S.K., \& C.L. Griffin, eds. (2004). Introducing feminist rhetorical scholarship. In Readings in feminist rhetorical theory. Thousand Oaks, CA: Sage. 1-6.
Frohmann, B. (1994). The social construction of knowledge organization: The case of Melvil Dewey. In Knowledge organization and quality management: Proceedings of the third international ISKO conference, 20-24 June 1994, Copenhagen, Denmark. (Advances in Knowledge Organization, vol. 4.) Eds. Hanne Albrechtsen and Susanne Oernager. Frankfurt/Main: Indeks Verlag.

Kublik, A., Clevette, V., Ward, D., and Olson, H.A. (2003). Adapting dominant classifications to particular contexts. Cataloging \& Classification Quarterly, 37(1/2), 13-31.

Intner, S. S. \& Futas, E. (1996). The role and impact of Library of Congress Classification on the assessment of women's studies collections. Library Acquisitions: Practice \& Theory, 20(3), 267-279.

Wiegand, W. (1996). Irrepressible reformer: A biography of Melvil Dewey. Chicago: American Library Association. 